\title{
Fire-Adaptation in Hypocerides nearcticus Borgmeier and Anabarhynchus hyalipennis hyalipennis Marquart and New Notes about the Australian "Smoke Fly" Microsania australis Collart (Diptera: Phoridae, Therevidae and Platypezidae)
}

\author{
David Klocke*, Anke Schmitz and Helmut Schmitz
}

Institut für Zoologie, Universität Bonn, Germany

\begin{abstract}
This study deals with the fire-adapted behaviour of three Australian fly species on freshly burnt areas in Western Australia.

The smoke fly, Microsania australis Collart (Platypezidae), swarms in smoke plumes. Our field studies present new notes about the ecology of Microsania, especially with respect to its ecological niche. Additionally, Hypocerides nearcticus Borgmeier (Phoridae) aggregated on burnt sites immediately after the fire forming distinct swarms outside smoke plumes, relatively close to the surface of burnt substrates, where copulations took place frequently. Unlike M. australis and $H$. nearcticus, Anabarhynchus hyalipennis hyalipennis Marquart (Therevidae) was always observed individually. Flies landed on ash-covered soil around burnt logs often near to hot spots, seemingly depositing eggs into the ash. This study documents fire-adaptation within the families of Phoridae and Therevidae for the first time, indicating a relation between pyrophilous behavioural patterns and reproduction in fire-adapted flies. Our results show that each fly species exploits a certain ecological niche which was created by the fire.
\end{abstract}

Additionally, this is the first record of H. nearcticus in Australia.

Keywords: Pyrophilous insects, Microsania, flies, forest fire, smoke.

\section{INTRODUCTION}

Some insects have a so-called pyrophilous (i.e. "fireloving") behaviour. These species are found more frequently in burnt than in unburnt habitats. More than 50 species have been described as pyrophilous so far and about $50 \%$ of these species are most probably attracted by the open fire, hot ash or smoke [1]. Pyrophilous species can be found within the orders Hymenoptera [2], Heteroptera, Lepidoptera, Coleoptera and Diptera [1].

Within the Diptera, pyrophilous behaviour has been documented for members of the genus Hormopeza (Empididae) and Microsania (Platypezidae) [3-5] and for a single species of the Asteriidae and Drosophilidae [1]. Pyrophilous behaviour can be adaptive because the burnt trees can be used as breeding material, nutrient sources like phloem or fast-growing post-fire fungi are easy to exploit, and competition is reduced. The microclimate is modified because the lack of the leafy canopy means that solar radiation heats up the darkened soil which results in higher ambient temperatures $[1,6,7]$.

The members of the genus Microsania, which has a global distribution, are known as "smoke flies" because these flies are highly attracted by smoke. Pyrophilous behaviour was first documented for M. stigmaticalis Zetterstedt [8] and later for several other species of the genus [3].

*Address correspondence to this author at the Institut für Zoologie, Universität Bonn, Germany; Tel: +49(0)228/735494; Fax: +49(0)228/735458;

E-mail:dklocke@uni-bonn.de
Smoke originating from different sources leads to aggregation and swarming of dozens of Microsania flies within the smoke plume. In contrast, in the absence of smoke, these flies are extremely rare $[3,9]$. Mating within smoke plumes has rarely been observed [10] and there are only few publications about copulas settling on warm ashes $[11,12]$.

Microsania is not only attracted to hot smoke, but also lingers on smoke-saturated clothes and is attracted to "coldsmoke" (an aerosol-bomb-dispensed smoke concentrate) that is used by bee keepers [13]. These observations have been interpreted as suggestive of an olfactory orientation towards smoke-enriched air. Four species of the genus, including the small (2.2 mm in length) and endemic M. australis Collart, are described for Australia [14].

Apart from Microsania australis, two other Dipteran species, Hypocerides nearcticus Borgmeier (Phoridae) and Anabarhynchus hyalipennis Marquart (Therevidae) were observed and collected on freshly burnt areas in Western Australia.

Hypocerides nearcticus is a small fly with a body length of about $2.0 \mathrm{~mm}$. Phorid larvae feed on a great variety of decaying organic matter. H. nearcticus is widely distributed, known from the US, Panama, Papua New Guinea and Spain [15], Jemen [16] and Sweden [17] and until now, has not been documented for Australia.

Anabarhynchus hyalipennis hyalipennis has a body length of about $9 \mathrm{~mm}$. The genus Anabarhynchus is known from Australia, New Caledonia, Fiji, Papua New Guinea, and New Zealand and A. hyalipennis hyalipennis is widely 
distributed within Australia [18]. Therevid species are generalists and found in a variety of habitats including coastal scrubs, sandy ocean beaches and also sandy lake shores and river beds [19]. However, they are relatively rare within these habitats. The slender, worm-like larvae are very mobile and move quickly through sand and loose soil [19]. They live mainly in the soil close to the surface and live predacious [20]; feeding on annelids and numerous insect species (mainly beetle larvae). Little is known about the food of the adult Australian therevid flies. Most probably, flies feed on honeydew, flower nectar and pollen.

In contrast to Microsania australis, pyrophilous behaviour has not been recorded for Hypocerides nearcticus and Anabarhynchus hyalipennis hyalipennis. In this paper we describe pyrophilous behaviour in these species. Adult flies are attracted by forest fires and invade a freshly burnt area immediately following a fire. This is the first evidence for pyrophile within the Phoridae and Therevidae.

\section{METHODS}

All locations in which flies were observed and collected were situated on freshly burnt areas close to Perth in western Australia. Both, observation and trapping of flies took place in February of the years 2006 - 2009. Observation sites were burnt forests dominated by Eucalyptus or forests where Eucalyptus trees were mixed with Melaleuca ericifolia, Allocasuarina species or Banksia species, respectively. Freshly burnt areas in swamps or near lake shores were examined as well.

Burnt sites were inspected on the same day or up to five days after the fire. Without exception, smouldering material and smoke were still present. Air temperatures varied between 28 and $37{ }^{\circ} \mathrm{C}$; humidity was between $30 \%$ and $50 \%$.

Microsania australis and $H$. nearcticus were observed for 10 to 20 minutes before specimens were captured with a net or an aspirator. The behaviour of several single A. hyalipennis hyalipennis was also observed and additional flies which approached the locale were caught with a net or by hand. All flies were stored in $70 \%$ ethanol.

Localities were sketched, photographed with a digital camera $\left(\mathrm{HP}^{\circledR}\right.$ Photosmart R742) and thermographed with an infrared camera (IR Flexcam T, infrared solutions ${ }^{\circledR}$ ) which has a calibrated temperature range from -20 to $+350{ }^{\circ} \mathrm{C}$. Thermographs show differences in surface temperature indicated by false colours (Fig. 1). "Hot spots" were defined as spots where temperatures exceeded $80{ }^{\circ} \mathrm{C}$.

Determination of M. australis was done by Dr. Daniel J. Bickel (Australian Museum, Sidney). H. nearcticus was determined by Dr. Henry Disney (Department of Zoology, University of Cambridge). Determination of A. hyalipennis hyalipennis was done by Dr. Shaun Winterton (School of Biological Sciences, University of Queensland).

\section{RESULTS}

\section{Microsania australis}

Microsania australis was found exclusively on freshly burnt sites. Nearly all flies were observed in swarms of about 20 to 100 individuals. Swarm diameters were around $50 \mathrm{~cm}$. These swarms formed in horizontal smoke plumes that originated from smouldering logs or superficial roots of burnt Eucalyptus trees. Surface temperatures of the smouldering wood often exceeded $200{ }^{\circ} \mathrm{C}$.

Swarms were formed in a distance of up to $1 \mathrm{~m}$ from the origin of the smoke plume at a height between 10 and 150 $\mathrm{cm}$ above the soil, depending on the vertical distribution of the smoke-plume. When the plume was displaced by changes of the wind direction, individuals re-aggregated in the plume within one minute. Localities where $M$. australis was found are given in Table $\mathbf{1 .}$

Once, $M$. australis was found in a locality where no smoke could be detected, a burnt-out knothole in a fallen burnt Eucalyptus tree. The walls of the cavity were gutted by fire and dozens of flies were observed entering and leaving
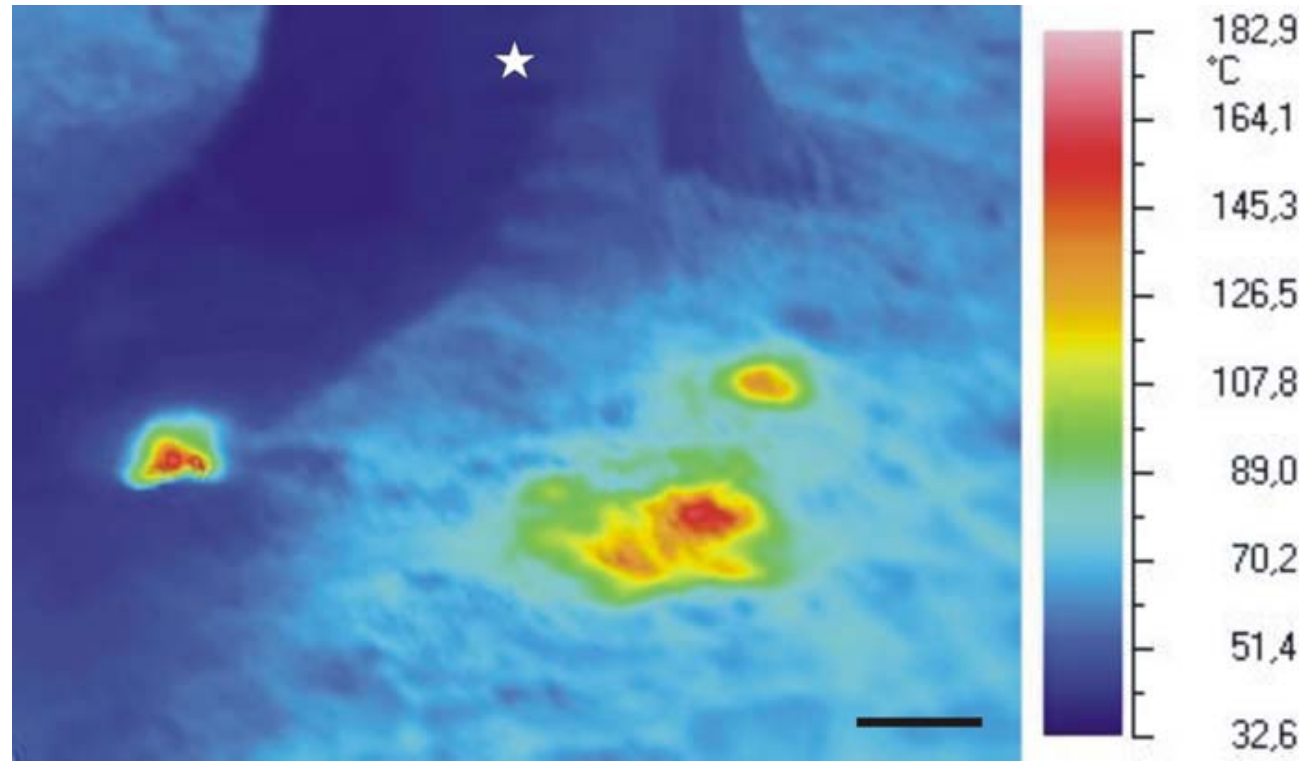

Fig. (1). Infrared thermograph of a spot where Anabarhynchus hyalipennis hyalipennis was found. The base of a Eucalypt tree (asterisk) and smouldering superficial roots are visible. Differences in temperature are indicated by false colours. Scale bar $0.2 \mathrm{~m}$. 
Table 1. Localities of Microsania australis, Hypocerides nearcticus and Anabarhynchus hyalipennis hyalipennis

\begin{tabular}{|c|c|c|c|c|c|}
\hline Species & Location & Vegetation/Site & Place & Date & Time \\
\hline \multirow[t]{6}{*}{ M. australis } & $\begin{array}{l}\text { Surveyors Rd. } \\
\text { Mundaring }\end{array}$ & E. ${ }^{\text {a }}$ spec., old-growth & Stub of burnt E. spec, $\mathrm{g}^{\mathrm{b}}, \mathrm{s}^{\mathrm{c}}$ & 2006-02-07 & 2:30 PM \\
\hline & Brookton HWY & Banksia spec. and E. spec. & Stub of burned E. spec, g, s & 2008-02-06 & 3:00 PM \\
\hline & Great S.- W.- HWY & E. marginata & Superficial roots of E. marginata, $\mathrm{g}, \mathrm{s}$ & $2008-02-13$ & $1: 30 \mathrm{PM}$ \\
\hline & \multirow[t]{2}{*}{ Chitna Rd, South } & \multirow[t]{2}{*}{ E. rudus near dry lake } & Tumbled fire-damaged E. rudus, g, s & 2009-02-08 & $12: 30 \mathrm{PM}$ \\
\hline & & & Stub of burned E. rudus, g, s & 2009-02-08 & 3:00 PM \\
\hline & Loch McNess & E. spec. near dry swamp & Superficial roots of fire-damaged E. spec., g, s & 2009-02-09 & 12:00 PM \\
\hline \multirow[t]{8}{*}{ H. nearcticus } & Brookton HWY & Banksia spec. and E.spec. & Base of fire-damaged E. spec. & $2008-02-06$ & 1:00 PM \\
\hline & Brand HWY & Banksia spec. and E. spec. & Base of fire-damaged E. spec. & $2008-02-16$ & 2:30 PM \\
\hline & \multirow[t]{2}{*}{ Perth hills, Mundaring } & \multirow{2}{*}{$\begin{array}{l}A .^{\mathrm{d}} \text { spec. and E. spec., old- } \\
\text { growth }\end{array}$} & Burned E. spec., s & $2009-02-01$ & 12:30 PM \\
\hline & & & Flat pit beside fire-damaged $A$. spec. & 2009-02-01 & $1: 00 \mathrm{PM}$ \\
\hline & \multirow[t]{2}{*}{ Chitna Rd, South } & \multirow[t]{2}{*}{ E. rudus near dry lake } & Base of fire-damaged E. rudus & 2009-02-08 & 11:00 AM \\
\hline & & & Stub of burned E. rudus & 2009-02-08 & 12:00 PM \\
\hline & \multirow[t]{2}{*}{ Loch McNess } & E. spec. near dry swamp & Fire-damaged log of fallen E. spec. & 2009-02-09 & $11: 30 \mathrm{AM}$ \\
\hline & & Dry swamp near lake & Pit in smouldering peaty soil & 2009-02-10 & 3:00 PM \\
\hline \multirow[t]{7}{*}{ A. hyalipennis } & $\begin{array}{l}\text { Surveyors Rd. } \\
\text { Mundaring }\end{array}$ & E. spec., old-growth & $\begin{array}{l}\text { Ash-covered soil around thin log of burned } \\
\text { E. spec., hs }{ }^{\mathrm{e}}, \mathrm{s}\end{array}$ & 2006-02-07 & 1:00 PM \\
\hline & $\begin{array}{l}\text { Hester Park,Canning } \\
\text { River }\end{array}$ & $\begin{array}{l}\text { E. rudis and Melaleuca erici- } \\
\text { folia }\end{array}$ & $\begin{array}{l}\text { Ash-covered soil around burned Eucalyptus } \\
\log , \text { hs }\end{array}$ & $2007-02-19$ & 2:00 PM \\
\hline & $\begin{array}{l}\text { Great South-West- } \\
\text { HWY }\end{array}$ & E. marginata & $\begin{array}{l}\text { Ash-covered soil around log of fire-damaged } \\
\text { E. spec., hs, s }\end{array}$ & $2008-02-13$ & $4: 30 \mathrm{PM}$ \\
\hline & Brand HWY & Banksia spec. and E. spec. & $\begin{array}{l}\text { Ash-covered soil around log of fire-damaged } \\
\text { E. spec., s }\end{array}$ & $2008-02-16$ & $1: 30 \mathrm{PM}$ \\
\hline & \multirow[t]{3}{*}{ Loch McNess } & \multirow[t]{3}{*}{ E. spec. near dry swamp } & $\begin{array}{l}\text { Ash-covered soil around log of fire-damaged } \\
\text { E. spec., hs }\end{array}$ & 2009-02-09 & 12:30 PM \\
\hline & & & $\begin{array}{l}\text { Ash-covered soil around log of fire-damaged } \\
\text { E. spec., g, hs, s }\end{array}$ & 2009-02-14 & 2:00 PM \\
\hline & & & $\begin{array}{l}\text { Ash-covered soil around burned out Eucalypt } \\
\log , \mathrm{g}, \mathrm{hs}\end{array}$ & 2009-02-14 & 3:30 PM \\
\hline
\end{tabular}

${ }^{\mathrm{a}}$ Eucalyptus; ${ }^{\mathrm{b}}$ glowing; ' $\mathrm{c}$ visible smoke; ${ }^{\mathrm{d}}$ Allocasuarina; ${ }^{\mathrm{e}}$ hot spots.

the cavity through an opening with a diameter of about 10 $\mathrm{cm}$. It was not possible to determine the sex of the flies. Although there was neither a hot spot nor visible smoke within at least $3 \mathrm{~m}$ around the cavity, the described behaviour continued for at least four days.

\section{Hypocerides nearcticus}

Hypocerides nearcticus was found on burnt areas immediately and up to six days after the fire. Without exception, smouldering organic material was present in the burnt areas. Flies aggregated in swarms of about 10 to 100 individuals and swarming took place over burnt wood or burnt soil. The flies flew close to the ground (height up to $10 \mathrm{~cm}$ ) or crawled very quickly over the surface. Copulations were often observed.
Copulas and single individuals frequently entered small openings in the burnt soil or burnt wood. When copulas entered an opening, they afterwards mostly left it together. Usually the duration of stay in these openings was only some seconds and according to our observations, flies rarely seemed to remain inside the substrate. Typical swarming sites for $H$. nearcticus were the bases of fire-damaged trees having heavily burnt surfaces and whose surrounding soil was covered by ash. Hypocerides nearcticus often swarmed at the border area between ash and log. Flies entered cracks in the log and its superficial roots as well as small cavities in the ash. Patches that were sheltered from the wind, like burnt out caverns in fire-damaged trees and flat pits next to burnt logs, seemed to be preferred swarming sites. Frequently smouldering wood and smoke were present within a distance 
of several meters. However, flies usually did not swarm inside smoke plumes or close to hot spots (Table $\mathbf{1}$ ).

Flies were also observed at two sites swarming close to smouldering material releasing smoke. At these spots, $H$. nearcticus was captured together with $M$. australis. At one site a matured Eucalyptus tree had been extinguished by fire fighters the evening before. As a result, the base of the tree was surrounded by a moist silt consisting of ash and sand. Due to the water content and shadow cast by the tree, the surface of the soil had a much lower $\left(26^{\circ} \mathrm{C}\right)$ temperature than the nearby ground which was exposed to the sun $(60$ $\left.{ }^{\circ} \mathrm{C}\right)$. Thousands of $H$. nearcticus were observed swarming close to the base of the tree. Flies were mostly running but also flying a few $\mathrm{mm}$ above the moist soil. Flies seemed to have more contact to the soil than observed in other places.

\section{Anabarhynchus hyalipennis hyalipennis}

Anabarhynchus hyalipennis was observed on freshly burnt areas immediately and up to six days after the fire. Flies were routinely encountered in areas of ash-covered soil around fire-damaged Eucalyptus trees. Without exception, tree trunks or superficial roots contained hot spots with surface temperatures between $80{ }^{\circ} \mathrm{C}$ and more than $360{ }^{\circ} \mathrm{C}$. In most cases visible smoke was released from those spots. Flies landed in an area of approximately $2 \mathrm{~m}$ around $\operatorname{logs}$ containing one or more hot spots and moved into small sheltered niches in the bark, the undersides of dry leaves or dead branches and wedge-shaped clefts between the lower surface of a fallen tree and the ash covered ground (Table 1). In these shelters, the flies inserted their abdomen into the ash while performing vibration-like movements and finally took off after 5 to $20 \mathrm{~s}$. During this behavioural pattern, flies showed very small flight zones and could sometimes be captured by hand.

\section{DISCUSSION}

\section{Behaviour of Microsania australis on Burnt Areas}

The behaviour we observed in M. australis is mainly consistent with the descriptions made by Kessel [3]. The ecological function of fire-associated swarming behaviour is unclear. As $M$. australis is very rare in unburnt areas but common in burnt habitats, it has been postulated that smoke plumes serve as "mating points" for the sexes [3, 9]. However, copulations have been observed only rarely $[10,12]$.

There is only sparse evidence that Microsania oviposits on burnt material, as single females were observed settling on lukewarm ash or smouldering embers [21, 22]. In the present study, it has been observed that large numbers of flies frequented a torched cavity in a Eucalyptus log. No smoke or nearby glowing spots could be detected.

Based on our observations we suggest that after aggregation in distinct swarms within smoke plumes, single flies or small groups of flies leave the smoke plume heading for openings in burnt wood or soil where oviposition takes place presumably.

Due to the fire, biotic and abiotic factors in the habitat are suddenly changed. M. australis could benefit from that, as the larvae might be able to feed on burnt plant parts or fast-growing post-fire fungi. Exploiting such food sources early after the fire should be of advance over flies that do not show the suggested pyrophilous behaviour and invade into the burned habitat much later. Hence, the pyrophilous behaviour of M. australis can be considered as highly adaptive.

\section{Pyrophilous Behaviour of Hypocerides nearcticus}

This is the first Australian record for H. nearcticus and there are no publications about pyrophilous behaviour in the whole family of Phoridae. However, a few $H$. nearcticus were caught in a Malaise-trap on a burnt site in Sweden, three weeks after a burn in an old-growth pine forest [17], but there were no smoke plumes or hot spots present when the trap was installed (Viklund, 2008, personal communication).

In this study, it is documented that individuals aggregate in small swarms where copulation is frequent. Individual flies and copulas enter openings in burnt wood and soil suggesting that they oviposit in these substrates. So far, nothing is known about the larval stages of $H$. nearcticus. Many phorids breed in moist decaying matter and there are some species whose larvae feed on fungi and are pests of cultivated mushrooms [23]. H. nearcticus seems to be highly attracted by moist substrate. Larvae might use decaying organic matter after a fire as a food source.

As suggested for $M$. australis, larvae of $H$. nearcticus might also feed on burnt plant parts or post-fire fungi. Exploiting such food sources early after the fire should be of an advance over flies that do not show the described fireloving behaviour. Consequently, the fire-loving behaviour should be of evolutionary advantage.

\section{Oviposition in Anabarhynchus hyalipennis hyalipennis}

This is the first documentation that a therevid fly is strongly attracted to hot spots, ash and smoke on freshly burnt areas and we observed females of A. hyalipennis hyalipennis inserting their abdomen into the ash accompanied by vibration-like movements suggestive of oviposition behaviour. The purpose of moving into small sheltered niches could be an attempt to minimise the risk of being captured by a predator during oviposition. Alternatively, the ecological meaning of oviposition near structures sticking out of the ash thereby casting shade could be to make sure that the larvae could develop in a favourable microclimate.

It is not known which stimulus may cause the attraction of A. hyalipennis towards the ash-covered soil around burnt logs. As ash, smouldering wood and hot spots were present in all localities, either olfactory cues or sensitivity to infrared radiation as described for some pyrophilous beetles and bugs [24-27] may be important. I have examined A. hyalipennis for infrared organs. Yet, none were found (Klocke D, unpublished data). However, the existence of infrared organs cannot be ruled out.

It is known, that therevid larvae are predators, feeding on insect larvae and annelids but preferring Coleoptera larvae. They are found mainly in sand or soil close to the surface [20].

As hot spots on smouldering superficial roots were present in all localities, it can be assumed that at least a part of the roots are killed by the fire, serving as a food for a variety of insect larvae. Consequently, larvae of A. hyalipennis would find a lot of prey at these spots and might be able to 
exploit this valuable source of food much earlier than predacious larvae of flies that do not show the described pyrophilous behaviour. Hence, the suggested oviposition, immediately after the burn, should result in a higher fitness.

\section{CONCLUSION}

In the present study, new notes about the pyrophilous behaviour of the "smoke fly" $M$. australis are presented, suggesting ovipositing in burnt wood.

Moreover, another species, H. nearcticus, was observed showing a distinct pyrophilous behaviour which at the same time represents the first proof for pyrophilous behaviour within the family of Phoridae. Although $H$. nearcticus aggregates in swarms on freshly burnt areas, its swarming behaviour differs significantly from that of $M$. australis. Swarming in H. nearcticus serves for mating and the burnt substrate seems to be used for ovipositing. In addition, this is the first record for a distribution of H. nearcticus in Australia.

The therevid fly A. hyalipennis landed on ash-covered soil close to burnt logs, seemingly in order to deposit eggs into the ash. Our observations represent the first evidence of a fire-adapted behaviour in this species and also in the whole family of Therevidae.

\section{ACKNOWLEDGEMENTS}

We thank the Department of Environment and Conservation (DEC) for the permission to visit bushfires and for providing all necessary equipments and information enabling us to work on burnt areas. In particular, we thank Mike Cantelo and Brian Inglis from the DEC Office in Wanneroo, Perth, as well as Neil Burrows and Paul Van Heurck from the DEC Science Division for generous support and continuous interest in our work. We are grateful to Daniel Bickel, Shaun Winterton and Henry Disney for the determination of flies. This study was supported by a grant of the German Federal Ministry of Education and Research (BMBF) to H.S.

\section{REFERENCES}

[1] Wikars L-O. Effect of forest fire and the ecology of fire-adapted insects. Acta University Uppsala Comprehensive Summaries of Uppsala Dissertations from the Faculty of Science and Technology 1997; vol. 272: p. 35.

[2] Brues CT. Vespid wasps (Eumenes curvata) attracted to smoke. Psyche 1950; 57: 114-5

[3] Kessel EL. American smoke flies (Microsania: Clythiidae). Wasman Collector 1947; 7: 23-30.

[4] Kessel EL. The response of Microsania and Hormopeza to smoke (Diptera: Platypezidae and Empididae). Pan-Pacific Entomologist 1960; 36: 67-8.
[5] Collin JE. Hormopeza obliterata Zetterstedt associated with Melanophila acuminata DeGeer on burning pines in Berkshire. Entomologist's Monthly Magazine 1918; 54: 278-9.

[6] Wikars L-O. Skogsbränder och insekter. Entomologisk Tidskrift 1992; 113(4): 1-11.

[7] Esseen P-A, Ehnström B, Ericsson L, Sjöberg K. Boreal forests. Ecol Bull 1997; 46: 16-47.

[8] Severin G. Notes sur le Microsania stigmaticallis Zett. (Dipt.). Bull Soc Entomol Belg 1921; 3: 178-9.

[9] Bickel DJ. Smoke flies (Diptera: Platypezidae) and the Sydney bushfires. Aust Entomol 1996; 23(2): 77-8.

[10] Snoddy EL, Tippins HH. On the ecology of a smoke fly, Microsania imperfecta. Ann Entomol Soc Am 1968; 61(5): 1200.

[11] Morley C. True smoke flies. Transactions of the Suffolk Naturalists' Society 1938; 1: 78.

[12] Chandler PJ. Some dipterous opportunists at Windsor Forest, Berks: The attractions for flies of bonfires, wood ash and freshly cut logs. Entomologist's Gazette 1978; 29: 253-7.

[13] Kessel EL. Microsanias attracted to cold smoke (Diptera: Platypezidae). Wasmann J Biol 1960; 18: 312-3.

[14] Chandler PJ. The Oriental and Australasian species of Platypezidae (Diptera). Invert Taxon 1994; 8: 351-434.

[15] Disney RHL, Blasco-Zumeta J. Two exotic tramp species of scuttle fly (Diptera, Phoridae) recorded in Spain. Entomologist's Monthly Magazine 2004; 140: 307-8.

[16] Disney RHL. Insects of Arabia Scuttle flies (Diptera: Phoridae) Part I: All genera except Megaselia. Fauna Arabia 2006; 22: 473521.

[17] Ulefors S-O, Viklund B, Disney RHL. Hypocerides Schmitz (Diptera, Phoridae) in Sweden, the first Palaearctic record of the genus. Entomologist's Monthly Magazine 2001; 137: 218.

[18] Lyneborg L. The Australian stiletto-flies of the Anabarhynchus genus-group (Diptera: Therevidae). Entomonograph 2001; 13: 256 pp.

[19] Lyneborg L, Ed. Therevidae (Insecta: Diptera). Auckland: DSIR Plant Protection 1992.

[20] English K. Notes on the morphology and biology of Anabarhynchus fasciatus Macq. and other Australian Therevidae. Proc Linn Soc NSW 1950; 75: 345-59.

[21] Edwards FW. Microsania pectinipennis Mg. (Dipt., Platypezidae) attracted to bonfire smoke. J Soc Br Entomol 1934; 1: 31-2.

[22] Collart A. Observations sur les Microsania (Dipt., Platypezidae). Bull Ann Soc R Entomol Belg 1958; 94: 297-8.

[23] Johal K, Disney RHL. Phoridae (Diptera) as pests of cultivated oyster mushrooms (Agaricales, Pleorotaceae) in India. Bull Entomol Res 1994; 84(2): 247-54.

[24] Evans WG. Infra-red receptors in Melanophila acuminata DeGeer. Nature 1964; 202: 211

[25] Schmitz H, Schmitz A, Trenner S, Bleckmann H. A new type of insect infrared organ of low thermal mass. Naturwissenschaften 2002; 89(5): 226-9.

[26] Schmitz H, Schmitz A, Bleckmann H. A new type of infrared organ in the Australian "fire-beetle" Merimna atrata (Coleoptera: Buprestidae). Naturwissenschaften 2000; 87(12): 542-5.

[27] Schmitz A, Gebhardt M, Schmitz H. Microfluidic photomechanic infrared receptors in a pyrophilous flat bug. Naturwissenschaften 2008; 95(5): 455-60.

(c) Klocke et al.; Licensee Bentham Open.

This is an open access article licensed under the terms of the Creative Commons Attribution Non-Commercial License (http://creativecommons.org/licenses/by-nc/3.0/) which permits unrestricted, non-commercial use, distribution and reproduction in any medium, provided the work is properly cited. 